\title{
Can nuclear power deliver?
}

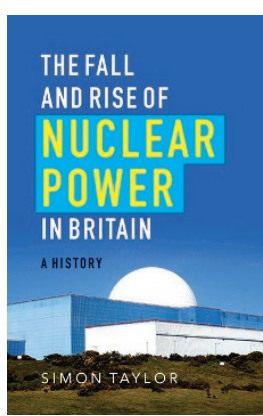

\author{
The Fall and Rise \\ of Nuclear Power \\ in Britain: A History \\ by Simon Taylor \\ UIT CAMBRIDGE 256PP. \\ E19.99
}

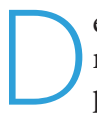
espite nuclear power's technological radicalism and immense physical productivity, it remains just another way of boiling water to generate electricity. Although it could offer some advantages energy security and industrial leadership over other forms of electricity generation, in the end it must be broadly competitive with them if it is to be a sustainable option (unless, of course, it is a cover for weapons production). Putting it simply, nuclear has to be cheap, clean and safe. In The Fall and Rise of Nuclear Power in Britain, Simon Taylor sets out to explore the history of the UK's approach to this controversial power source and whether it can meet these criteria.

On the subject of whether nuclear is 'clean', Taylor argues that it is, in relation to greenhouse gas emissions - on a par with most renewables and way ahead of any currently available fossil fuel use. However, nuclear is much less clean in terms of radioactive waste and Taylor acknowledges the absence of serious progress in the UK in finding a long-term solution to waste management. As to safety, the international record of the nuclear industry is arguably not bad in relation to other generating technologies, and Taylor argues that it is sufficiently safe to stay in contention.

So leaving proliferation, safety and waste to one side, the issue for this book is simple: is nuclear power in the UK cheap enough? The straightforward answer given is that nuclear has never been cheap enough to compete genuinely with alternative sources, but that we are nevertheless stuck with it, using the (in)famous TINA (there is no alternative) argument. This argument, hinging on the high ambitions the UK holds for emission reductions, has been a familiar one in recent times. Because the UK is committed to an $80 \%$ reduction in carbon emissions by 2050 , and as other low-carbon options look unlikely to get us near this, we seem to need nuclear because it alone can fill the gap, being a reliable bulk source of lowcarbon power. Although getting to $80 \%$ is immensely challenging, a 'no alternative' framing is arguably never credible.

Besides, Taylor's view that nuclear will be reliably able to deliver a lot of low-carbon electricity is less than convincing; it is substantially at odds with his own, often very clear-sighted, analysis. Specifically, he worries about the credibility of a 'programme' of nuclear construction that will involve at least three different reactor designs, when the pool of relevant skilled labour and project management capability is already being stretched by other infrastructure projects and will be made much worse by the large volume of nuclear construction necessary to validate the 'bulk supply' argument. Additionally, the first new nuclear project, Hinkley Point, originally due to be generating by 2017, has already had its completion date pushed back to 2025. Given all of this, the reliability of nuclear in providing large amounts of low-carbon power is doubtful.

\section{Where the book really gets interesting is in its detailed coverage of the way in which the current Hinkley Point \\ project has been negotiated.}

Overall, the book presents a clear and well-written analysis of the economic and financial status of nuclear power in the UK since its inception. Taylor covers the 70 years from 1945 to 2015, although his primary emphasis is contemporary: only 42 pages are devoted to the years 1945-2002, whereas over 150 pages cover the post-2002 period. This latter period is where the author is most at home, and is most convincing. For the pre-2002 period, Taylor shows, not for the first time, that the economic status of nuclear power was consistently presented in a way that was always misleading and frequently entirely bogus. The preparations for the privatization of electricity in the late 1980s finally revealed that nuclear power had always been substantially more expensive than its then main rival, coal.
But where the book really gets interesting is in its detailed coverage of the way in which the current Hinkley Point project - a twin-unit European pressurized water reactor station of some 3,300 MW - has been negotiated between the utility company EDF and the UK government. Taylor demonstrates with great clarity how the government's refusal to help share the (dominant) construction cost risk with the developer, combined with its need to push ahead with nuclear power, has pushed it into a highly unfavourable deal with EDF. EDF are currently the only developer, and are well aware of the government's weak bargaining position. The consequence is that consumers will be forced to pay a substantial premium essentially a high and fixed price for power - until around 2060. Arguing that this is significantly more expensive than necessary, Taylor dissects for the lay reader the technicalities of the loan guarantees, the 'contract for difference', the unconvincing EU/UK view that nuclear suffers from market failure, and the other financial details surrounding the deal. His title for a late section of the book, 'The world's most expensive power station', serves as a fitting summary for the project.

While this book is lucid, very wellwritten and often entertaining, it is not without problems. It is only sporadically referenced and omits important details like the nuclear 'moratorium' from 1989 to 1994. It also fails to discuss two primary driving forces behind pro-nuclear UK policy over the whole 70 years: the twin convictions that, politically, nuclear power was part of a state enterprise, including nuclear weapons, that guaranteed the UK a place at the 'top table' internationally; and that, technologically, the goal was to develop plutonium-based fast neutron reactors that would liberate us from dependence on nature by 'breeding' more fuel than consumed. Nonetheless, despite its framing in terms of the 'no alternative' narrative, Taylor's cool and dispassionate financial and economic analysis of nuclear technology in the UK, especially over the past few years, is an excellent and even enthralling read.

\section{REVIEWED BY GORDON MACKERRON}

Gordon MacKerron is at the Science Policy

Research Unit, School of Business, Management and Economics, University of Sussex, UK. 